\title{
Narcolepsy treatment: pharmacological and behavioral strategies in adults and children
}

\author{
Christian Franceschini ${ }^{1} \cdot$ Fabio Pizza ${ }^{2,3} \cdot$ Elena Antelmi ${ }^{2,3} \cdot$ Maria Claudia Folli $^{1} \cdot$ Giuseppe Plazzi ${ }^{2,3}$ (D)
}

Received: 27 March 2019 / Revised: 6 June 2019 / Accepted: 1 July 2019 / Published online: 10 July 2019

(C) Springer Nature Switzerland AG 2019

\begin{abstract}
Narcolepsy is a disabling, rare, and chronic sleep disorder, currently classified as distinct central nervous system hypersomnia in narcolepsy type 1 (NT1) and narcolepsy type 2 (NT2). Although today a reliable pathogenic hypothesis identifies the cause of NT1 as an autoimmune process destroying hypocretin-producing cells, there is no cure for narcolepsy, and the symptomatic pharmacological available treatments are not entirely effective for all symptoms. Behavioral therapies play a synergistic role in the disease treatment. We here review the available therapeutic options for narcolepsy, including symptomatic pharmacological treatments as well as behavioral and psychosocial interventions that could help clinicians improve the quality of life of patients with narcolepsy in adulthood and childhood.
\end{abstract}

Keywords Narcolepsy $\cdot$ Adults $\cdot$ Children $\cdot$ Pharmacological treatment $\cdot$ Psychological treatment $\cdot$ Behavioral treatment

Narcolepsy is a disabling, rare, and chronic sleep disorder mainly characterized by excessive daytime sleepiness (EDS). According to ICSD-III, narcolepsy is classified as distinct central nervous system hypersomnia in narcolepsy type 1 (NT1), formerly narcolepsy with cataplexy caused by a selective loss of hypothalamic neurons producing hypocretin, and narcolepsy type 2 (NT2), formerly narcolepsy without cataplexy and with normal hypocretin levels [1].

Hypocretin is a neurotransmitter involved in the regulation of sleep, body homeostasis, emotions, and behavior [2-4] with wide projections to numerous areas of the brain, including the locus coeruleus (norepinephrine neurons), tuberomammillary nucleus (histaminergic neurons), raphe

This article is part of the Topical Collection on Excessive Daytime Sleepiness

Giuseppe Plazzi

giuseppe.plazzi@unibo.it

1 Department of Medicine and Surgery, University of Parma, Parma, Italy

2 Department of Biomedical and Neuromotor Sciences, Alma Mater Studiorum, University of Bologna, Bologna, Italy

3 IRCCS Istituto delle Scienze Neurologiche di Bologna, Bologna, Italy nucleus (serotonergic neurons), and ventral tegmental areas (dopaminergic neurons) [5]. Physiologically, hypocretin not only plays an excitatory role on the central nervous system but also modulates serotonin, histamine, dopamine, acetylcholine, GABA, and glutamate activity [6]. Loss of hypocretin may lead to abnormal functioning of the sleep-wake regulation systems, which provokes EDS and other abnormal manifestations of rapid eye movement (REM), such as sleep paralysis or hypnagogic/ hypnopompic hallucinations.

The onset of NT1 usually begins when the patient is from 10 to 20 years old. The disease prevalence differs between geographical areas, mostly affecting the Japanese population $(0.16-0.18 \%)$ [7] and presents a rare disease prevalence in the USA and Europe (0.02-0.06\%) [8].

Also in pediatric patients, NT2 seems to be less frequent compared with NT1 [9].

Currently, the most reliable pathogenic hypothesis identifies the cause of NT1 as an autoimmune process triggered by both genetic and environmental risk factors, based on the strong association with human leukocyte antigen (HLA) DQB $1 * 0602$ and other genetic features [10]. On the other hand, the pathophysiology of NT2 is still not clear.

NT1 patients suffer from significant medical comorbidities, affecting the endocrinological (e.g., obesity, precocious puberty) [11], cardiovascular (e.g., non-dipper blood pressure profile) [12], and psychiatric (e.g., anxiety/mood 
disturbances, psychosis) $[13,14]$ domains. A constellation of altered neuropsychological processes as well as other psychological aspects contributes to a detrimental impact on the patient's quality of life and achievements [15]. Recent data on patient-oriented outcomes disclosed that non-sleep-related aspects (i.e., decreased sexual activity or memory complaints) [16] have a major impact on the disease perception and quality of life. Thus, new disease management strategies in a multifaceted and multidisciplinary approach are needed.

To date, there is no cure for narcolepsy, and the treatment methods that are currently available are not entirely effective for all symptoms. In this context, behavioral therapies play a synergistic role in the disease management. The main target of this review is to discuss symptomatic pharmacological treatments and behavioral and psychosocial interventions for EDS and cataplexy in adulthood and childhood and the core narcolepsy symptoms, in order to help clinicians in their clinical practice.

\section{Methods}

The first author $(\mathrm{CF})$ conducted a research for topical literature published until 31 January 2019 in the following scientific databases: PubMed, Web of Science, and PsycINFO. Several search terms were included but were not limited to "narcolepsy," "narcolepsy with and w/o cataplexy," "NT1," "NT2," and clinical management, treatment, pharmacotherapy, counseling, peer support, and cognitive behavioral therapy.

Inclusion criteria for this research were as follows: publications in English with an available full text and adult and childhood populations. Moreover, several guidelines have been used to better analyze the management of narcolepsy. The most relevant studies, according to the authors' opinion, were selected to give an overview avoid redundancy.

\section{Pharmacological treatment}

Up to date, the pharmacological treatment of narcolepsy is usually necessary for the rest of the patient's life. Available well-founded treatments are solely symptomatic and primarily focused on core symptoms: EDS and cataplexy. A great number of largely used medications are not approved by the European Medicine Agency (EMA) or Food and Drug Administration (FDA), and the application of these drugs is limited to expert recommendations, in off-label use. In this article, we will try to synthesize the main treatments available to date for the daily clinical consultation of both adults and children afflicted with narcolepsy and the status of recommendation in the guidelines only for the adult patients.

\section{EDS pharmacological treatment in adults}

\section{First-line treatments}

\section{Modafinil}

Modafinil selectively stimulates wake-generating sets in the hypothalamus [17] thanks to an increase of dopamine in the extracellular concentration, but the exact mechanism of action is still unknown [18]. Several pieces of evidence demonstrated that a dose of 200-400 mg/day of modafinil improved EDS, averagely increased sleep latencies on Maintenance of Wakefulness Test (MWT), and enhanced the subjective perception of improvement on Clinical Global Improvement of Change (CGI-C) [19-23].

Usually, the intake of modafinil starts with $100 \mathrm{mg}$ (in the morning) to gradually move to a split dosing $(100+$ $100)$ in the morning (after breakfast) and at lunch time. After several weeks, it can be progressively increased up to $200+200[22,23]$.

Compared with other stimulants, modafinil has less abuse potential and is generally well tolerated. Typical side effects are headache, nausea, tension /anxiety, and insomnia [24-27]. It is important to remember that modafinil decreases the efficacy of oral contraceptives; thus, higher ethinylestradiol or alternative contraceptive methods are suggested [28].

In adults, modafinil is approved by the FDA and EMA in treating both NT1 and NT2 patients [29].

\section{Armodafinil}

The drug is an R-enantiomer of modafinil with a specific target, i.e., D2 receptor partial agonist. The clinical advice is to take a single dose of armodafinil in the morning, starting with $100 \mathrm{mg}$ up to a maximum of $250 \mathrm{mg} /$ day. Studies show how the subjective sleepiness (calculated by Epworth Sleepiness Scale) decreased from 16.9 to 12.6 after 12 months of therapy $[19,20,29]$.

In adults, armodafinil is approved by the FDA in treating both NT1 and NT2 patients [30].

\section{Pitolisant}

Pitolisant is an $\mathrm{H} 3$ receptor antagonist/inverse agonist. Its main action is mediated at the presynaptic level through the activation of histaminergic neurons in the brain, which are involved in a large variety of functions, including wakefulness, attention, and memory [31]. Pitolisant has been shown 
to be as effective in treating daytime sleepiness [32, 33] as modafinil, and it is also efficacious in decreasing cataplexy.

Prescription guidelines suggest taking pitolisant in the morning with breakfast, in a single dose starting with $9 \mathrm{mg}$ up to $36 \mathrm{mg} /$ day in a few weeks. Experts seem to agree in identifying the dose of $36 \mathrm{mg} /$ day as the most effective dose. Commonly, the desired effect is reached within a couple of weeks. To date, there still is no evidence of a clinical longterm efficacy. Pitolisant does not seem to have drug abuse potential and is well tolerated. Common side effects include headache, insomnia, and nausea. Headache and nausea are often noticed at the beginning of the treatment $[32,33]$. Due to the potential interaction with oral contraceptives, other contraceptive methods should be prescribed.

In adults, pitolisant is approved by the EMA both in NT1 and NT2 patients [34].

\section{Sodium oxybate or gamma hydroxybutyrate}

Sodium oxybate is a gamma-hydroxybutyric acid Bsubtype (GABAb) receptor agonist in the central nervous system, particularly diffused in the hypothalamus and basal ganglia. The exact mechanism of action of sodium oxybate is not clear yet, but it has been associated with an increase in slow-wave sleep, decrease in the number of awakenings, reduction of the REM sleep period, and important improvements of sleep efficiency [35, 36].

Sodium oxybate improves cataplexy, EDS, and other narcolepsy symptoms, especially disturbed nocturnal sleep, where improvements can be seen first. The recovery from EDS is not as instantaneous as with stimulant drugs, but it is visible only after many weeks/months, also because the right therapeutic dosage must be identified for each specific patient [37]. Different studies indicate reduced EDS and an increased level of alertness [38, 39]. Another retrospective study [40] demonstrated that the combination of modafinil + sodium oxybate produced a significant improvement in subjective somnolence (Epworth Sleepiness Scale (ESS)). The mean MWT sleep latency was compared with sodium oxybate + placebo in NT1 and NT2 patients. Nevertheless, clinical experience communicates a less strong alerting effect of sodium oxybate compared with modafinil [41, 42].

To date, sodium oxybate can only be found in liquid form and is supposed to be taken twice per night. Therefore, the patient should be woken up during the night (a clock may be helpful) in order to take the second dose. The recommended starting dose is $4.5 \mathrm{~g} /$ night divided into two equal doses of $2.25 \mathrm{~g}$, the first one administered right before sleeping and the second one $2.5-3 \mathrm{~h}$ later. Gradually, an additional $1.5 \mathrm{~g} / \mathrm{night}$ per week should be added to the original starting dose. Improvements should become evident after 4-8 weeks of treatment (6-9 g/night).
The most common side effects include nausea, dizziness/ confusion, weight loss, enuresis, anxiety, and depressive symptoms [29]. For some patients, the medication may taste too salty. In this case, physicians recommend adding water flavors or reducing the suggested dose in order to avoid nausea. If nausea is severe, a 5-HT3 antagonist, such as ondansetron, may be advised [19, 20].

In adults, sodium oxybate is approved by the FDA both in NT1 and NT2 patients for the treatment of cataplexy and of EDS [43]. EMA approved sodium oxybate only for NT1.

\section{Second-line treatments}

\section{Methylphenidate}

Methylphenidate increases dopamine and norepinephrine transmission. It is mostly used when other kinds of medications reveal to be ineffective. Only a few studies [44-46] demonstrated significant differences in the ability of staying awake and active in narcoleptic patients compared with control subjects. Remarkable is the effect on sleepiness, evident within few days even at the lowest dosage $(10 \mathrm{mg})$; however, a higher dose up to 60 can be used to reach a clinically meaningful response $[19,20]$.

Typical side effects of methylphenidate are tachycardia, hypertension, sweating, palpitations, irritability, hyperactivity, mood swings, weight loss, anorexia, and insomnia [29].

The prescription suggests a starting dose of methylphenidate of $10-20 \mathrm{mg}$ in the morning with breakfast and additional $10-20 \mathrm{mg}$ at lunch. Maximum recommended dosage is $60 \mathrm{mg}$, usually spread in 2-4 portions over the day [47]

In adults, methylphenidate is approved for the treatment of EDS by the EMA (but not registered in all EU countries) and FDA both in NT1 and NT2 patients [29].

\section{Third-line treatments}

\section{Amphetamines and other therapeutic options}

Among commonly used drugs, amphetamines are surely one of the cheapest $[19,20]$. Nevertheless, it is well known that these drugs bring along many risks, including high abuse potential, which can lead to cardiovascular adverse effects (selegiline [48]; reboxetine [49]; ephedrine, pemoline, L-carnitine [50]).

In some European countries [19], dextroamphetamineanother kind of amphetamine-is approved for treating EDS, with an indicated starting dose of $5 \mathrm{mg}$ to a maximum of $60 \mathrm{mg}$ per day [51].

In France, mazindol was available for the treatment of EDS in narcolepsy until 2016, with a therapeutic dosage that varied from 1 to $4 \mathrm{mg}$ per day. Hepatotoxicity has been described for 
this drug [52, 53], and new results on the risk-benefit ratio are needed in narcolepsy.

Finally, the FDA recently approved two different admixtures: the first one combines amphetamine and dextroamphetamine (Adderall ${ }^{\mathrm{TM}}$ ), while the other one has amphetamine sulfate as main active ingredient $\left(\mathrm{Evekeo}^{\mathrm{TM}}\right)$ [29].

\section{Solriamfetol}

Solriamfetol (75 up to $150 \mathrm{mg} /$ day) is a new drug that has appeared on the market in 2019. It is a selective inhibitor of the reuptake of dopamine and norepinephrine, a dual action that makes it different from other wake-promoting agents. Moreover, it does not promote the release of monoamines as amphetamine stimulants do. In phase 3 controlled clinical trials in adult patients afflicted with narcolepsy, solriamfetol reduced patient-reported EDS as measured on the ESS and improved wakefulness as measured by the objective MWT [54].

Typical side effects of solriamfetol are headache, nausea, decreased appetite, nasopharyngitis, dry mouth, and anxiety. In adults, solriamfetol is approved for the treatment of EDS by the FDA [55].

In Table 1, an overview of pharmacological treatments for EDS in NT1 and NT2 patients is shown.

\section{Cataplexy pharmacological treatment in adults}

\section{First-line treatments}

\section{Sodium oxybate or gamma hydroxybutyrate}

Several discoveries showed a noteworthy subjective reduction of the number of cataplectic attacks and cataplexy intensity with sodium oxybate administration in NT1 patients $[19,20]$.
This effect can mostly be seen after weeks to months of therapy with a dose-dependent effect, as confirmed in several studies [56-61] and in the longest follow-up study (18 months) [62]. A sudden withdrawal of sodium oxybate does not lead to status cataplecticus.

\section{Venlafaxine}

Venlafaxine is a selective norepinephrine reuptake inhibitor and is usually prescribed in NT1 patients only by clinical recommendation $[19,20]$. Usually, the anticataplectic effect reaches its peak in a few days, is well tolerated, and has some typical side effects: increased blood pressure, headache, dry mouth, nausea, and dizziness.

The prescription suggests a starting dose of $37.5 \mathrm{mg}$ up to a maximum dosage of $225 \mathrm{mg}$, taken in the morning [63]. Typically, withdrawal may produce a rebound effect up to a "cataplectic status" [64], i.e., subcontinuous invalidating cataplexy episodes.

Despite the wide use, venlafaxine is not approved in treating narcolepsy.

\section{Pitolisant}

In a recent study [65], the efficacy of pitolisant in daily cataplexy attacks has been documented and confirmed by the reduction of attacks' frequency compared with placebo in NT1 patients. In addition, the anticataplectic effects were recently confirmed in a well-designed randomized, double-blind, placebo-controlled trial conducted on 105 patients suffering from narcolepsy with cataplexy, where a reduction in the average frequency of cataplexy was shown [66].

Pitolisant has been approved by the EMA in NT1 for the treatment of cataplexy [67].
Table 1 Therapy

recommendation for EDS in adult NT1 and NT2

\begin{tabular}{|c|c|c|c|c|c|c|}
\hline \multirow[t]{2}{*}{ EDS in adults } & \multirow[t]{2}{*}{ Treatment } & \multirow[t]{2}{*}{ Daily dosage } & \multicolumn{2}{|l|}{ FDA } & \multicolumn{2}{|l|}{ EMA } \\
\hline & & & NT1 & NT2 & NT1 & NT2 \\
\hline \multirow[t]{4}{*}{ First line } & Modafinil & $100-400$ up to $600 \mathrm{mg}$ & $\mathrm{X}$ & $\mathrm{X}$ & $\mathrm{X}$ & $\mathrm{X}$ \\
\hline & Armodafinil & $100 \mathrm{up}$ to $250 \mathrm{mg}$ & $\mathrm{X}$ & $\mathrm{X}$ & & \\
\hline & Pitolisant & 9up to $36 \mathrm{mg}$ & & & $\mathrm{X}$ & $\mathrm{X}$ \\
\hline & Sodium oxybate & $4.5-9 \mathrm{~g}$ (split dose at night) & $\mathrm{X}$ & $\mathrm{X}$ & $\mathrm{X}$ & \\
\hline Second line & Methylphenidate & $10-40 \mathrm{up}$ to $60 \mathrm{mg}$ & $\mathrm{X}$ & $\mathrm{X}$ & $X^{\mathrm{a}}$ & \\
\hline \multirow[t]{4}{*}{ Third line } & Dextroamphetamine & $5 \mathrm{up}$ to $60 \mathrm{mg}$ & & & & $X^{b}$ \\
\hline & Adderall $^{\mathrm{TM}}$ & & & & & $\mathrm{X}$ \\
\hline & Evekeo $^{\mathrm{TM}}$ & & & & & $\mathrm{X}$ \\
\hline & Solriamfetol & $75 \mathrm{up} \mathrm{to} 150 \mathrm{mg}$ & & & & $\mathrm{X}$ \\
\hline
\end{tabular}

${ }^{\mathrm{a}}$ In not all European countries; ${ }^{\mathrm{b}}$ only in Germany and Switzerland 
Table 2 Therapy

recommendation for cataplexy in adult NT1

\begin{tabular}{|c|c|c|c|c|}
\hline Cataplexy in adults & Treatment & Daily dosage & $\begin{array}{l}\text { FDA } \\
\text { NT1 }\end{array}$ & $\begin{array}{l}\text { EMA } \\
\text { NT1 }\end{array}$ \\
\hline \multirow[t]{3}{*}{ First line } & Sodium oxybate & $4.5-9 \mathrm{~g}$ (split dose at night) & $\mathrm{X}$ & $\mathrm{X}$ \\
\hline & Venlafaxine & $37.5 \mathrm{up}$ to $225 \mathrm{mg}$ & & \\
\hline & Pitolisant & 9 up to $36 \mathrm{mg}$ & & $\mathrm{X}$ \\
\hline \multirow[t]{3}{*}{ Second line } & Fluoxetine & $10-20 \mathrm{up}$ to $60 \mathrm{mg}$ & & \\
\hline & Citalopram & $10-20 \mathrm{up}$ to $40 \mathrm{mg}$ & & \\
\hline & Clomipramine & $10-25$ up to $75 \mathrm{mg}$ & & a \\
\hline
\end{tabular}

${ }^{\mathrm{a}}$ Only in Germany

\section{Second-line treatments}

Other antidepressants: fluoxetine, citalopram, and clomipramine

The main selective serotonin reuptake inhibitors (SSRIs) used in NT1 are fluoxetine (10-20 up to $60 \mathrm{mg} /$ day) and citalopram (10-20 up to $40 \mathrm{mg} /$ day) $[19,20]$. However, side effects and tolerance should not be underestimated, as they may represent a disadvantage in clinical practice [47, 68-69]. Main side effects are excitation, gastrointestinal problems, insomnia, and sexual difficulties. Sudden discontinuation can lead to status cataplecticus [70]; thus, extremely careful clinical care should be taken of patients, especially if elderly.

Since the 1960s, clomipramine (10-25 up to $75 \mathrm{mg} /$ day) has been the main tricyclic antidepressant used to treat cataplexy with a convincing reduction of attacks [19, 20, 71-73]. Reported side effects are dry mouth, sweating, constipation, diarrhea, tachycardia, weight gain, hypotension, difficulty in urinating, and impotence.
Fluoxetine, citalopram, and clomipramine are not accepted as a treatment for narcolepsy with the exception of clomipramine in Germany [29].

In Table 2, we summarize pharmacological indications for cataplexy in patients with NT1.

\section{EDS pharmacological treatment in childhood}

Today, sodium oxybate is the only approved drug by the FDA for EDS treatment in children and adolescents. Nevertheless, in clinical practice, no other medications are available or EMA approved. The selection of medications in the pediatric population works only on an empiric, off-label basis.

In Table 3, we summarize pharmacological indications for EDS and cataplexy in children with NT1 and NT2.

\section{Modafinil and armodafinil}

The use of both drugs is not approved by the FDA below the age of 16, but off-label use is common in the pediatric
Table 3 Therapy

recommendation for EDS and cataplexy in narcoleptic children

\begin{tabular}{|c|c|c|c|c|c|c|}
\hline \multirow[t]{2}{*}{ Children } & \multirow[t]{2}{*}{ Treatment } & \multirow[t]{2}{*}{ Daily dosage } & \multicolumn{2}{|l|}{ FDA } & \multicolumn{2}{|l|}{ EMA } \\
\hline & & & NT1 & NT2 & NT1 & NT2 \\
\hline \multirow[t]{6}{*}{ EDS } & Modafinil* & $50 \mathrm{up}$ to $400 \mathrm{mg}$ & & & & \\
\hline & Armodafinil* & $50 \mathrm{up}$ to $400 \mathrm{mg}$ & & & & \\
\hline & Pitolisant* & $4.5 \mathrm{up}$ to $36 \mathrm{mg}$ & & & & \\
\hline & Sodium oxybate & $2-8 \mathrm{~g}$ (split dose at night) & $\mathrm{X}$ & & & \\
\hline & Methylphenidate* & 10 up to $40 \mathrm{mg}$ & & & & \\
\hline & Dextroamphetamine * & 2.5 up to $20 \mathrm{mg}$ (twice a day) & & & & \\
\hline \multirow[t]{6}{*}{ Cataplexy } & Sodium oxybate & $2-8 \mathrm{~g}$ (split dose at night) & $\mathrm{X}$ & & & \\
\hline & Imipramine* & $10-100 \mathrm{mg}$ & & & & \\
\hline & Clomipramine* & $10-150 \mathrm{mg}$ & & & & \\
\hline & Protriptyline* & $2.5-5 \mathrm{mg}$ & & & & \\
\hline & Fluoxetine* & $10-30 \mathrm{mg}$ & & & & \\
\hline & Venlafaxine* & $3.75-75 \mathrm{mg}$ & & & & \\
\hline
\end{tabular}

* off label 
population under medical care $[19,20]$. In children, physicians recommend $50-400 \mathrm{mg} /$ day in two doses per day to support children in school performance (morning intake), after-school activities, and homework (early afternoon intake). There is no rebound in hypersomnolence when modafinil/ armodafinil administration needs to be stopped suddenly. Common side effects of modafinil/armodafinil include headache, nausea, vomiting, and red or purple skin rash that gradually spreads (Stevens-Johnson syndrome), which has been reported only in one case [74]. Stevens-Johnson syndrome is a delayed hypersensitivity reaction that develops from few days to weeks after beginning the therapy.

The only piece of evidence is a level 4 study by Ivanenko and colleagues [75]. Modafinil therapy in children and adolescents contributes to a subjective improvement of EDS. Furthermore, the study showed objective improvement in the average sleep latency on the MSLT from a baseline of $6.6 \pm 3.7 \mathrm{~min}$ to $10.2 \pm 4.8 \mathrm{~min}$.

\section{Pitolisant}

Up to now, the efficacy and safety of pitolisant in reducing residual EDS in children and adolescents have been the subject of an ongoing phase 2 study with primary completion estimated in December 2019.

Pitolisant showed fewer side effects in adolescents during the first week of treatment compared with modafinil: insomnia, headache, leg pain, hot flushes, and hallucinations. Moreover, it seems to be better tolerated [11, 32, 75, 76].

\section{Sodium oxybate or gamma hydroxybutyrate}

Sodium oxybate is a medication for NT1 children that has proved to be effective not only in cataplexy and EDS symptoms but also in monotherapy or in association with other stimulant drugs for narcolepsy [77].

To receive access to the medication, prescription of sodium oxybate requires registration and training, and distribution to the patient is all made through a central pharmacy. The reason behind this compulsory procedure is that the drug has been associated with misuse/abuse in some clinical cases. Therefore, experts also recommend clinicians and physicians to educate their patient before starting any treatment. Sometimes it may be helpful to involve nursing staff as well. On the other hand, the family is also asked to make sure to be at home when the drug is delivered and that the shipment is securely locked down. Up to now, as stated above, the drug has been purchasable only in liquid form, which can lead to some problems as its taste may be too salty for children. Suggested doses vary from 2 to $8 \mathrm{~g}$ per night. The amount must be divided into two doses also in children: the first one should be administered right before the patient goes to bed, whereas the second one $2.5-3 \mathrm{~h}$ after the first one.
Although a reduction of symptoms has been demonstrated (EDS and cataplexy) in 88\% of NT1 children [78, 79], sodium oxybate treatment maintains a high risk ratio: sleep walking, sleep enuresis, exacerbation of sleep apnea, tremor, constipation, exacerbation of pre-existing depressive tendencies, weight loss, nausea, irritability, and episodes of sleep drunkenness. Treatment cessation generally does not have rebound effects [77].

The FDA recently approved sodium oxybate for treating both cataplexy and EDS in narcolepsy children (FDA) [80].

\section{Amphetamine and methylphenidate}

These drugs are considered stimulants but they are also used to treat attention-deficit/hyperactivity disorder in children and adults [81]. The mechanism of action of both amphetamine (dextroamphetamine) and methylphenidate involves enhanced release of dopamine and to a lesser extent norepinephrine from the presynaptic terminals and the inhibition of their reuptake $[19,20]$. Recommended dosages are 2.5 to $20 \mathrm{mg}$ twice a day for dextroamphetamine and 10 to $40 \mathrm{mg}$ divided into two doses for methylphenidate. In adults, there are three phase 2 studies and four level 5 studies that support the effectiveness of traditional stimulants in treating EDS [20]. The possible side effects of stimulants include tics, anorexia, headache, nervousness, insomnia, and weight loss [82], and stimulants are recommended to be avoided in children with a diagnosed heart disease [83, 84]. Stimulants have not been FDA approved for their use in children below the age of six.

\section{Cataplexy pharmacological treatment in childhood}

Today, sodium oxybate is the only FDA-approved drug for cataplexy treatment in children and adolescents. Nevertheless, in clinical practice, there are no other medications available or EMA approved. The selection of medications in the pediatric population works only on an empiric, offlabel basis.

\section{Tricyclic agents}

The commonly used agents that provide a modest effect in controlling cataplexy are imipramine (10-100 mg/day), clomipramine (10-150 mg/day), and protriptyline $(2.5-5 \mathrm{mg} /$ day). Side effects include dryness of mouth, blurring, drowsiness, orthostatic hypotension, and weight gain [19, 20, 85].

\section{Selective serotonin reuptake inhibitors}

The common agent is fluoxetine (10-30 mg/day) [19, 20], typically used when the patient shows an anxiety and 
depression component in their life. Common side effects are nervousness, insomnia, and tremor. Abrupt interruption or irregular intake of tricyclics and selective serotonin reuptake inhibitors (SSRI) may trigger a particular condition in the patient called "status cataplecticus" [86].

\section{Selective norepinephrine reuptake inhibitors}

The common agent is venlafaxine (3.75-75 $\mathrm{mg}$ once a day) $[19,20]$. The use in adolescents and children must be extremely controlled, considering that an increased risk of suicide is documented in adolescents; moreover, adverse interactions with monoamine oxidase inhibitors are described, causing dizziness, headache, and insomnia [87].

Only few observational studies [88, 89] described the successful treatment of cataplexy in children (from 3 to 12 years old), with good response to the therapy without significant adverse events for a long time (2 years of follow-up).

\section{Sodium oxybate or gamma hydroxybutyrate}

For additional information, please see the previous paragraph "EDS pharmacological treatment in childhood".

\section{Immunotherapy}

Several pieces of evidence support an autoimmune mechanism underlying the onset of NT1, offering a rationale for the use of immunomodulation therapy with intravenous immunoglobulin G (IVIG) close to disease onset. Only a few investigators [39, 90-92] have tried IVIG in early-onset narcoleptic patients to understand its therapeutic efficacy, but the results are controversial due to the small sample size, openlabel design, and self-report observations. The results suggest a potential improvement in frequency and severity of cataplexy and ameliorated daytime sleepiness, data further confirmed by new evidence [93]. Given the possibility of spontaneous improvement of cataplexy [94], more controlled studies are indicated. We do not know about other immunosuppressant therapies used in narcolepsy patients (i.e., T cell immunity).

\section{Non-pharmacological treatment}

Serious and important psychosocial costs linked to narcolepsy have been described [15]: indeed, narcolepsy is associated with an increased risk of work- and traffic-related accidents [95], sexual dysfunctions [96], neuropsychological alterations $[95,97,98]$, and an overall significant reduction in the life quality [99-101]. Clinical guidelines of several countries (UK and European Association of Neurology for Europe and American Academy of Sleep Medicine for North America consensus) $[19,20,102]$ encourage the application of cognitive and behavioral actions, how to schedule naps, as complementary therapies to reduce the negative effects that follow the disease and gain a better adherence to drug therapy. In particular, guidelines proposed by UK consensus [102] present a symptomatological approach to manage narcoleptic symptoms: increase the patient's knowledge of the disease, scheduled naps, nocturnal sleep duration, support in planning work, and psychosocial support. On the contrary, guidelines proposed by the American Academy of Sleep Medicine [20] do not describe any behavioral measure, although the need to improve the quality of life of patients with narcolepsy is identified.

Thus, in these paragraphs, we summarize the main proposed psychological techniques, all aiming at helping the patient in managing their symptoms. In Table 4, an overview of non-pharmacological treatment in narcoleptic patients is shown.

\section{Behavioral treatment for EDS}

Several studies showed that the best way to improve daytime sleepiness is to schedule daytime naps $[19,20]$. Naps ranging
Table 4 Overview of nonpharmacological treatment in narcolepsy

\begin{tabular}{|c|c|}
\hline Non-pharmacological treatment & Target \\
\hline $\begin{array}{l}\text { Behavioral treatment for EDS (scheduled } \\
\text { daytime nap; sessions of sleep extension) }\end{array}$ & Decrease of daytime sleepiness attacks \\
\hline Cognitive therapy & $\begin{array}{l}\text { Decrease of the consequences that maintain symptoms and } \\
\text { affect the patient's daily life and help the patient cope with } \\
\text { his emotions }\end{array}$ \\
\hline Physical activity & $\begin{array}{l}\text { Decrease of daytime sleepiness attacks; regular sleep/wake } \\
\text { profile; weight gain; decrease cataplexy attack }\end{array}$ \\
\hline Counseling & $\begin{array}{l}\text { Reach adequate management and education of symptoms; } \\
\text { increase peer support }\end{array}$ \\
\hline Child and relatives & $\begin{array}{l}\text { Educate about narcolepsy, treatment, and self-care and offer a } \\
\text { specific support to the parental couple }\end{array}$ \\
\hline
\end{tabular}


from 15 to 20 min planned about two or three times per day are particularly effective in treating EDS and improving alertness [103-105]. Naps should not, however, extend beyond $30 \mathrm{~min}$, because longer naps may be unrefreshing and result in increased drowsiness $[9,105]$. Short naps benefited certain patients [106], whereas long naps increased nocturnal sleep in others [106]. As some people during the day need to stay focused on their tasks for a while, planned naps could sometimes reveal themselves to be an impractical solution.

Furthermore, it has been proposed that sessions of sleep extension be conducted for the treatment of EDS. The sleep satiation technique is based on the sleep homeostasis theory and consists of the scheduled extension of nocturnal sleep (nocturnal sleep period for 2 weeks: 10:00 pm to 6:00 a.m.) [107]. Sleep satiation is a technique that requires the detection of the behavior's frequency in order to identify the degree of sleepiness and the compilation of a sleep diary that determines the number of sessions. Then, continuous 1-day episodes are scheduled without light-dark cues. Improvements that follow naps and scheduled nocturnal sleep extension can be clarified by this behavioral disposition.

\section{Cognitive therapy}

The effectiveness of cognitive behavioral therapy (CBT) for narcolepsy has been demonstrated by multiple studies since 2001. This technique is aimed at identifying and possibly modifying the patient's dysfunctional cognitions and treatment adherence and identifying patients who are taking medications at appropriate times, maintaining good sleep hygiene, and taking scheduled naps [108]. In therapy, the impact that narcolepsy symptoms have on the quality of life, emotions, and other functional areas of the patient is highlighted [109, 110]. The first randomized study [111-113] applied self-report measures (i.e., the Epworth Sleepiness Scale, Ullanlinna Narcolepsy Scale, SF 36) in order to evaluate if a multicomponent (sleep satiation, nap training, cognitive restructuring, and problem-solving techniques) treatment provides better results than standard treatments (control group, 6 months and 1 year of treatment). In particular, the treatment group demonstrated a significant improvement not only regarding the quality of life (physical function, social function, vitality, and emotional role) but also in subjective reports of EDS.

A different study [114] was aimed at estimating how effective cognitive measures can be in coping with narcolepsy. Different techniques and behavioral experiments such as cognitive restructuring and intervention were supposed to reduce the safety behaviors that maintain the problem. Before starting CBT, researchers measured the characteristics of the patients' global quality of life and administered a questionnaire of beliefs and attitudes toward narcolepsy. Results showed that the CBT group had significantly superior $(p<0.005)$ post- treatment assessment scores than the control and drug treatment groups.

\section{Physical activity}

Physical exercise is recommended on a daily basis. Indeed, several studies demonstrated that it provides a positive impact on sleepiness, and it may be useful in order to keep track of the weight gain that commonly goes with the onset of NT1. An animal study showed that wakefulness in hypocretin knockout mice increased with wheel running. However, cataplexy increased as well $[85,115]$. An actigraphic study in NT1 children and adolescents documented that regular physical activity is associated with significant differences in children's sleepiness (lower subjective ESS-CHAD scores) and sleep/ wake profile (fewer daily NAPs and less time asleep during daytime) and does not trigger cataplexy [116].

\section{Cataplexy}

The CBT approach proposed the application of other symptomatic strategies, already used to treat other kinds of disorders, where the emotional or physiological component was central. Cataplexy is treated with systematic desensitization, one of these symptomatic strategies. CBT technique is based on a gradual approximation of situations, where the frequency and intensity of psychological dysfunctions increase. In treating cataplexy, CBT technique seems to be a good starting point to help the patient cope with his emotions.

Through systematic desensitization technique, researchers hierarchically organize stressful visual stimuli that the patient previously identified as situations that trigger cataplexy. The procedure starts with a mental illustration of situations that the patient fears (details are carefully specified), operated by both the clinician and the patient. Right after that, the clinician guides his patient, now deeply relaxed, to figure these scenes in his mind. Anxiety-related triggers in the different scenes gradually intensify.

Another procedure from the CBT approach called stimulus satiation has found application in cataplexy treatment: the clinician maintains what reinforces the cataplectic behavior in the patient until it loses its effect [117].

\section{Counseling}

Psychological counseling has proven to successfully help both the patient and the parents. To reach an effective symptom management and treatment, proper education of the patient is suggested, especially when he/she has just been diagnosed. Some key points should be to explain narcolepsy symptoms and how they can develop, vary, and affect relationships, work, and other relevant fields; what are the current available pharmacologic and behavioral therapies (e.g., good sleep 
hygiene) and their outcomes; and finally, other lifestyle factors that may affect the symptoms (e.g., the influence of alcohol on EDS) [118].

Peer support, defined as assistance provided by a person with experiential knowledge of the stressors and behaviors similar to the target population [118], is a form of psychosocial support that can improve the patient's knowledge and confidence in dealing with the disorder. Indeed, the support coming from sharing experiences with others can be constructive for both people with disabilities and their families [119, 120]. However, when the disorder is particularly rare, families and children may never have the opportunity to find this psychosocial support [121].

In Italy, narcoleptic patients can find excellent support in the Associazione Italiana Narcolettici ed Ipersonni (AIN onlus) (http://www.narcolessia.org/), born from the idea of a father of a 12-year-old child, Icilio Ceretelli, who had traveled for several years before joining the Bologna Center and receiving a diagnosis of narcolepsy. Today, the AIN is among the most active European Narcoleptic Patients Associations and continues to operate and provide key support and information to its members. Furthermore, we report the website address of other important European patient support associations:

- Austria: www.narkolepsie.at

- Belgium: www.narcolepsie-cataplexie.be

- Denmark:www.dansknarkolepsiforening.dk

- Finland: narkolepsia.fi

- France: www.anc-narcolepsie.com

- Germany: http://www.dng-ev.de/

- Ireland: http://soundireland.ie/

- Netherlands:www.narcolepsie.nl

- Norway: http://www.sovnforeningen.no/

- Poland: http://www.narkolepsja.pl/

- Spain: http://www.narcolepsia.org/

- Sweden: http://www.narkolepsiforeningen.se/

- Switzerland: https://www.snane.ch/

- UK: www.narcolepsy.org.uk

\section{Child and relatives}

In addition to symptoms, narcolepsy has often a negative impact on the child's psychological well-being. Moreover, parents may feel not enough prepared to deal with their child's pathology, a feeling that has mostly been reported before the intervention. In many cases, they did not receive enough support from professional figures, and their only encouragement has mainly come from close family members. This fact is probably due to the rareness of the disorder and the consequent focus that physicians have to invest in the diagnostic and medical challenges.
Kippola-Pääkkönen and colleagues [122] focused their research on the parents' expectations and perceived support of children affected by narcolepsy after a pandemic influenza in Finland. The intervention was aimed at combining both individual and group training: lectures, psychosocial counseling, group discussions, and skill training were some of the activities incorporated in the program, whose purpose was to educate about narcolepsy, treatments, and self-care.

A baseline and a final questionnaire was administered, collecting responses from 58 and 40 parents, respectively. Results highlighted not only a general worry about how the disease may impact their child's coping skills but also concern over not having enough time for their spouse. Support is received mostly from their spouses $(77 \%)$; thus, less comes from healthcare $(27 \%)$ or school personnel (23\%). Researchers suggest that an inpatient psychological intervention may help families in finding both informal and professional support.

\section{Conclusion}

NT1 is a chronic disorder characterized by EDS and cataplexy [1], but hypnagogic hallucinations, sleep paralysis, and disrupted nighttime sleep are also commonly reported by patients. Polysomnography recordings (PSG) can be noticed as well $[1,36,123]$. The occurrence of hallucinations and sleep paralysis shifts in frequency and impact in narcoleptic patients. In some cases, sodium oxybate revealed to be effective in reducing the number of hallucinations during the day [59], but also, other therapies, such as venlafaxine, have a good therapeutic effect [27].

A recent review of the literature on disrupted nighttime sleep in patients with narcolepsy has shown that nocturnal sleep is characterized-both in PSG and subjective reports - by frequent brief awakenings, awakenings, and a high level of N1 sleep, which is also associated with poor quality of sleep at night [124]. Sodium oxybate seems to be a gold standard treatment compared with modafinil in reducing disturbed sleep and consolidating nocturnal sleep [36, 123].

Today narcolepsy is still a complex disease, and despite new scientific discoveries about its pathophysiology, currently available treatments remain scarce and only symptomatic. On top of that, many drugs used in the clinical practice to cure children are still prescribed as "off-label" treatment.

Furthermore, new immune-modulating and hypocretinreplacement treatments should be verified more systematically, especially in patients and children with recent-onset narcolepsy in order to figure out their potential in treating the disease. Non-pharmacological interventions as well have been shown to contribute in helping patients and family members and to have a role in improving patients' quality of life; 
therefore, it is advisable for the future that outcome measures and multicompetent interventions should be guaranteed to the patients and their families.

The European Union has dedicated a priority area to rare disorders in health programs and policies, considering it fundamental to promote more equal attention between rare and common disorders in the effort to find a proper cure [125]. Today, the difficulty in finding good psychosocial support for people afflicted with rare disorders can be overcome thanks to inpatient psychosocial interventions, where patients can meet peers and receive professionally led support. Furthermore, developing support services in the local community may also be useful for the families and their children in order to deal with their daily challenges.

Acknowledgments Huge gratitude must be recognized to the memory of President of AIN, Icilio Ceretelli, who opened many eyes about real everyday challenges that narcoleptic patients and their families have to face and provided every person in need with the support they deserve.

Funding This work was supported by the FFABR (Franceschini).

Compliance with ethical standards The work is a literature review and complied with the tenets of the Declaration of Helsinki, as well as with the ethical standards of the journal.

Conflict of interest Giuseppe Plazzi participated in advisory board for UCB Pharma, Jazz pharmaceuticals, Bioprojet, and Idorsia outside the submitted work. The other authors have no potential financial conflict of interest to disclose.

\section{References}

1. AASM: American Academy of Sleep Medicine (2014) ICSD-3: international classification of sleep disorders, 3rd edn. American Academy of Sleep Medicine, Daniel

2. Hagan JJ, Leslie RA, Patel S, Evans ML, Wattam TA, Holmes S, Benham CD, Taylor SG, Routledge C, Hemmati P, Munton RP, Ashmeade TE, Shah AS, Hatcher JP, Hatcher PD, Jones DNC, Smith MI, Piper DC, Hunter AJ, Porter RA, Upton N (1999) Orexin A activates locus coeruleus cell firing and increases arousal in the rat. PNAS 96:10911-10916. https://doi.org/10.1073/pnas.96.19.10911

3. Sutcliffe JG, de Lecea L (2000) The hypocretins: excitatory neuromodulatory peptides for multiple homeostatic systems, including sleep and feeding. J Neurosci Res 62:161-168. https://doi. org/10.1002/1097-4547(20001015)62:2<161::AID-JNR1>3.0. $\mathrm{CO} ; 2-1$

4. Brown RE, Sergeeva O, Eriksson KS, Haas H (2001) Orexin A excites serotonergic neurons in the dorsal raphe nucleus of the rat. Neuropharmacology 40:457-459. https://doi.org/10.1016/S00283908(00)00178-7

5. Dye TJ, Gurbani N, Simakajornboon N (2018) Epidemiology and pathophysiology of childhood narcolepsy. Paediatr Respir Rev 25: 14-18. https://doi.org/10.1016/j.prrv.2016.12.005

6. Shibata M, Mondal MS, Date Y, Nakazato M, Suzuki H, Ueta Y (2008) Distribution of orexins-containing fibers and contents of orexins in the rat olfactory bulb. Neuroscience research, 61-99105. https://doi.org/10.1016/j.neures.2008.01.017
7. Tashiro T, Kanbayashi T, Iijima S, Hishikawa Y (1992) An epidemiological study of narcolepsy in Japanese. J Sleep Res 1:228

8. Mignot E (1998) Genetic and familial aspects of narcolepsy. Neurology 50:S16-S22. https://doi.org/10.1212/WNL.50.2_ Suppl_1.S16

9. Baumann CR, Mignot E, Lammers GJ, Overeem S, Arnulf I, Rye D, Dauvilliers Y, Honda M, Owens JA, Plazzi G, Scammell TE (2014) Challenges in diagnosing narcolepsy without cataplexy: a consensus statement. Sleep 37:1035-1042. https://doi.org/10. 5665/sleep. 3756

10. Miyagawa T, Tokunaga K (2019) Genetics of narcolepsy. Hum Genome Var 6:4. https://doi.org/10.1038/s41439-018-0033-7

11. Postiglione E, Antelmi E, Pizza F, Lecendreux M, Dauvilliers Y, Plazzi G (2018) The clinical spectrum of childhood narcolepsy. Sleep Med Rev 38:70-85. https://doi.org/10.1016/j.smrv.2017.04. 003

12. Dauvilliers Y, Jaussent I, Krams B, Scholz S, Lado S, Levy P, Pepin JL (2012) Non-dipping blood pressure profile in narcolepsy with cataplexy. PLoS One 7:e38977. https://doi.org/10.1371/ journal.pone.0038977

13. Fortuyn HA, Mulders PC, Renier WO, Buitelaar JK, Overeem S (2011) Narcolepsy and psychiatry: an evolving association of increasing interest. Sleep Med 12:714-719. https://doi.org/10.1016/ j.sleep.2011.01.013

14. Rocca FL, Pizza F, Ricc E, Plazzi G (2015) Narcolepsy during childhood: an update. Neuropediatrics 46:181-198. https://doi. org/10.1055/s-0035-1550152

15. Ingravallo $\mathrm{F}$, Gnucci $\mathrm{V}$, Pizza $\mathrm{F}$, Vignatelli L, Govi A, Dormi A, Pelotti S, Cicognani A, Dauvilliers Y, Plazzi G (2012) The burden of narcolepsy with cataplexy: how disease history and clinical features influence socio-economic outcomes. Sleep Med 13:1293-1300. https://doi.org/10. 1016/j.sleep.2012.08.002

16. Ton TG, Watson NF, Koepsell TD, Longstreth WT (2014) Narcolepsy and the sickness impact profile: a general health status measure. Sleep Sci 7:5-12. https://doi.org/10.1016/j.slsci.2014.07. 001

17. Scammell TE, Estabrooke IV, McCarthy MT et al (2000) Hypothalamic arousal regions are activated during modafinilinduced wakefulness. J Neurosci 20:8620-8628. https://doi.org/ 10.1523/JNEUROSCI.20-22-08620.2000

18. Wisor J (2013) Modafinil as a catecholaminergic agent: empirical evidence and unanswered questions. Front Neurol 4:139. https:// doi.org/10.3389/fneur.2013.00139

19. Billiard M, Bassetti C, Dauvilliers Y, Dolenc-Groselj L, Lammers GJ, Mayer G, Pollmächer T, Reading P, Sonka K; EFNS Task Force (2006) EFNS Task Force. EFNS guidelines on management of narcolepsy. Eur J Neurol 13:1035-1048. https://doi.org/10. 1111/j.1468-1331.2006.01473.x

20. Morgenthaler TI, Kapur VK, Brown T et al (2007) Standards of practice committee of the AASM. Practice parameters for the treatment of narcolepsy and other hypersomnias of central origin. Sleep 30:1705-1711. https://doi.org/10.1093/sleep/30.12.1750

21. Schwartz JR, Feldman NT, Bogan RK (2005) Dose effects of modafinil in sustaining wakefulness in narcolepsy patients with residual evening sleepiness. J Neuropsychiatry ClinNeurosci 17: 405-412. https://doi.org/10.1176/jnp.17.3.405

22. Schwartz JR, Feldman NT, Bogan RK, Nelson MT, Hughes RJ (2003) Dosing regimen effects of modafinil for improving daytime wakefulness in patients with narcolepsy. Clin Neuropharmacol 26:252-257

23. Schwartz JR, Nelson MT, Schwartz ER, Hughes RJ (2004) Effects of modafinil on wakefulness and executive function in patients with narcolepsy experiencing late-day sleepiness. Clin Neuropharmacol 27:74-79 
24. Billiard M, Besset A, Montplaisir J, Laffont F, Goldenberg F, Weill JS, Lubin S (1994) Modafinil: a double-blind multicentric study. Sleep 17:S107-S112

25. Broughton RJ, Fleming JA, George CF et al (1997) Randomized, doubleblind, placebo-controlled crossover trial of modafinil in the treatment of excessive daytime sleepiness in narcolepsy. Neurology 49:444-451

26. Randomized trial of modafinil as a treatment for the excessive daytime somnolence of narcolepsy: US Modafinil in Narcolepsy Multicenter Study Group (2000). Neurology 54:1166-1175. https://doi.org/10.1212/WNL.54.5.1166

27. Beusterien KM, Rogers AE, Walsleben JA, Emsellem HA, Reblando JA, Wang L, Goswami M, Steinwald B (1999) Health- related quality of life effects of modafinil for treatment of narcolepsy. Sleep 22:757-765

28. Palovaara S, Kivistö KT, Tapanainen P, Manninen P, Neuvonen PJ, Laine K (2000) Effect of an oral contraceptive preparation containing ethinylestradiol and gestodene on CYP3A4 activity as measured by midazolam 1-hydroxylation. Br J Clin Pharm 50: 333-337. https://doi.org/10.1046/j.1365-2125.2000.00271.x

29. Kallweit U, Bassetti CL (2017) Pharmacological management of narcolepsy with and without cataplexy. Expert Opin Pharmacother 18:809-817. https://doi.org/10.1007/s11940-015-0347-4

30. Harsh JR, Hayduk R, Rosenberg R, Wesnes KA, Walsh JK, Arora S, Niebler GE, Roth T (2006) The efficacy and safety of armodafinil as treatment for adults with excessive sleepiness associated with narcolepsy. Curr Med Res Opin 22:761-774. https:// doi.org/10.1185/030079906X100050

31. Lin J-S, Dauvilliers Y, Arnulf I, Bastuji H, Anaclet C, Parmentier R, Kocher L, Yanagisawa M, Lehert P, Ligneau X, Perrin D, Robert P, Roux M, Lecomte JM, Schwartz JC (2008) An inverse agonist of the histamine $\mathrm{H}(3)$ receptor improves wakefulness in narcolepsy: studies in orexin-/- mice and patients. Neurobiol Dis 30:74-83. https://doi.org/10.1016/j.nbd.2007.12.003

32. Dauvilliers Y, Bassetti C, Lammers GJ, Arnulf I, Mayer G, Rodenbeck A, Lehert P, Ding CL, Lecomte JM, Schwartz JC (2013) Pitolisant versus placebo or modafinil in patients with narcolepsy: a double-blind, randomized trial. Lancet Neurol 12: 1068-1075. https://doi.org/10.1016/S1474-4422(13)70225-4

33. Szakacs Z, Dauvilliers Y, Mikhaylov V, Poverennova I, Krylov S, Jankovic S, Sonka K, Lehert P, Lecomte I, Lecomte JM, Schwartz JC, Poluektov M, Yakupov E, Kalinkin A, Aksu M, Yilmaz H, Benbir G, Wolynczyk-Gmaj D, Jernajczyk W, Staykov I, Tavarari AN (2017) Safety and efficacy of pitolisant on cataplexy in patients with narcolepsy: a randomised, double-blind, placebocontrolled trial. Lancet Neurol 16:200-207. https://doi.org/10. 1016/S1474-4422(16)30333-7

34. Syed YY (2016) Pitolisant: first global approval. Drugs 76:13131318. https://doi.org/10.1007/s40265-016-0620-1

35. Mamelak M, Escriu JM, Stokan O (1977) The effects of gammahydroxybutyrate on sleep. Biol Psychiatry 12:273-288

36. Roth T, Dauvilliers Y, Guinta D, Alvarez-Horine S, Dynin E, Black J (2017) Effect of sodium oxybate on disrupted nighttime sleep in patients with narcolepsy. J Sleep Res 26:407-414. https:// doi.org/10.1111/jsr.12468

37. Houghton WC, Scammell TE, Thorpy M (2004) Pharmacotherapy for cataplexy. Sleep Med Rev 8:355-366. https://doi.org/10.1016/j.smrv.2004.01.004

38. Mansukhani M, Kotagal S (2012) Sodium oxybate in the treatment of childhood narcolepsy-cataplexy: a retrospective study. Sleep Med 13:606-610. https://doi.org/10.1016/j.sleep.2011.10. 032

39. Dauvilliers Y, Carlander B, Rivier F (2004) Successful management of cataplexy with intravenous immunoglobulins at narcolepsy onset. Ann Neurol 56:905-908. https://doi.org/10.1002/ana. 20339
40. de Oliveira MM, Conti C, Prado GF (2016) Pharmacological treatment for Kleine Levin syndrome. Cochrane Database Syst Rev 25: 486-496. https://doi.org/10.1002/14651858.CD006685.pub4. 2016

41. Leu-Semenescu S, Le Corvec T, Groos E, Lavault S, Golmard JL, Arnulf I (2015) Lithium therapy in Kleine-Levin syndrome: an open-label, controlled study in 130 patients. Neurology 85: 1655-1662. https://doi.org/10.1212/WNL.0000000000002104

42. Trotti LM, Saini P, Bliwise DL, Freeman AA, Jenkins A, Rye DB (2015) Clarithromycin in $\mathrm{y}$-aminobutyric acid-related hypersomnolence: a randomized, cross-over trial. Ann Neurol 78:454 465. https://doi.org/10.1002/ana.24459

43. PDR.net (2016) Available from: https://www.fda.gov/Drugs/ DrugSafety/ucm332029.htm

44. Mitler MM, Shafor R, Hajdukovich R, Timms RM, Browman CP (1986) Treatment of narcolepsy: objective studies on methylphenidate, pemoline, and protriptyline. Sleep 9:260-264. https://doi. org/10.1093/sleep/9.1.260

45. Honda Y, Hishikawa Y, Takahashi Y (1979) Long-term treatment of narcolepsy with methylphenidate (Ritalin). Curr Ther Res 25: 288-298

46. Leonard BE, McCartan D, White J, King DJ (2004) Methylphenidate: a review of its neuropharmacological, neuropsychological and adverse clinical effects. Hum Psychopharmacol 19:151-180. https://doi.org/10.1002/hup.579

47. Mignot EJ (2012) A practical guide to the therapy of narcolepsy and hypersomnia syndromes. Neurotherapeutics 9:739-752. https://doi.org/10.1007/s13311-012-0150-9

48. Mayer G, Meier-Ewert K, Hephata K (1995) Selegeline hydrochloride treatment in narcolepsy. A double-blind, placebocontrolled study. Clin Neuropharmacol 18:306-319

49. Larrosa O, de la Llave Y, Barrio S, Granizo JJ, Garcia-Borreguero D (2001) Stimulant and anticataplectic effects of reboxetine in patients with narcolepsy: a pilot study. Sleep 24:282-285. https://doi.org/10.1093/sleep/24.3.282

50. Miyagawa T, Kawamura H, Obuchi M, Ikesaki A, Ozaki A, Tokunaga K, Inoue Y, Honda M (2013) Effects of oral Lcarnitine administration in narcolepsy patients: a randomized, double-blind, cross-over and placebo-controlled trial. PLoS One 8:e53707. https://doi.org/10.1371/journal.pone.0053707

51. Barateau L, Lopez R, Dauvilliers Y (2016) Management of narcolepsy. Curr Treat Opin Neurol 18:43. https://doi.org/10.1007/ s11940-016-0429-y

52. Shindler J, Schachter M, Brincat S, Parkes JD (1985) Amphetamine, mazindol, and fencamfamin in narcolepsy. BMJ 290:1167-1170

53. Alvarez B, Dahlitz M, Grimshaw J, Parkes JD (1991) Mazindol in long-term treatment of narcolepsy. Lancet Lond Engl 337:12931294

54. Thorpy MJ, Shapiro C, Mayer G, Corser BC, Emsellem H, Plazzi G, Chen D, Carter LP, Wang H, Lu Y, Black J, Dauvilliers Y (2019) A randomized study of solriamfetol for excessive sleepiness in narcolepsy. Ann Neurol 85:359-370. https://doi.org/10. 1002/ana.25423

55. Sleepfoundation.org (2019) Sleep apnea| National Sleep Foundation. [online] Available: https://www.sleepfoundation. org/sleep-disorders-problems/sleep-apnea

56. Boscolo-Berto R, Viel G, Montagnese S, Raduazzo DI, Ferrara SD, Dauvilliers Y (2012) Narcolepsy and effectiveness of gammahydroxybutyrate (GHB): a systematic review and meta-analysis of randomized controlled trials. Sleep Med Rev 16:431-443. https:// doi.org/10.1016/j.smrv.2011.09.001

57. Alshaikh MK, Tricco AC, Tashkandi M, Mamdani M, Straus SE, BaHammam AS (2012) Sodium oxybate for narcolepsy with cataplexy: systematic review and meta-analysis. J Clin Sleep Med 8: 451-458. https://doi.org/10.5664/jcsm.2048 
58. Scrima L, Hartman PG, Johnson FH Jr, Hiller FC (1989) Efficacy of gammahydroxybutyrate versus placebo in treating narcolepsy-cataplexy: double-blind subjective measures. Biol Psychiatry 26:331343

59. Lammers GJ, Arends J, Declerck AC, Ferrari MD, Schouwink G, Troost J (1993) Gammahydroxybutyrate and narcolepsy: a double-blind placebo-controlled study. Sleep 16:216-220. https://doi.org/10.1093/sleep/16.3.216

60. US Xyrem Multicenter Study Group (2002) A randomized, double-blind, placebo-controlled multicenter trial comparing the effects of three doses of orally administered sodium oxybate with placebo for the treatment of narcolepsy. Sleep 25:42-49. https:// doi.org/10.1093/sleep/25.1.42

61. US Xyrem Multicenter Study Group (2003) A 12-month, openlabel multicenter extension trial of orally administered sodium oxybate for the treatment of narcolepsy. Sleep 26:31-35. https:// doi.org/10.1093/sleep/26.1.31

62. Mayer G, Plazzi G, Iranzo Á, Ortega-Albás J, Quinnell T, Pesch H, Serralheiro P, Schlit AF, Wuiame D, Bentz JWG (2018) Longterm compliance, safety, and tolerability of sodium oxybate treatment in patients with narcolepsy type 1: a postauthorization, noninterventional surveillance study. Sleep 41(9). https://doi.org/ 10.1093/sleep/zsy128

63. Pillen S, Pizza F, Dhondt K, Scammell TE, Overeem S (2017) Cataplexy and its mimics: clinical recognition and management. Curr Treat Options Neurol 19:23. https://doi.org/10.1007/s11940017-0459-0

64. Wang J, Greenberg H (2013) Status cataplecticus precipitated by abrupt withdrawal of venlafaxine. J Clin Sleep Med 15:715-716. https://doi.org/10.5664/jcsm.2848

65. Kollb-Sielecka M, Demolis P, Emmerich J, Markey G, Salmonson T, Haas M (2017) The European Medicines Agency review of pitolisant for treatment of narcolepsy: summary of the scientific assessment by the committee for medicinal products for human use. Sleep Med 33:125-129. https://doi.org/10.1016/j.sleep.2017. 01.002

66. Szakacs Z, Dauvilliers Y, Mikhaylov V et al (2017) HARMONYCTP study group. Safety and efficacy of pitolisant on cataplexy in patients with narcolepsy: a randomised, double-blind, placebocontrolled trial. Lancet Neurol 16:200-207. https://doi.org/10. 1016/S1474-4422(16)30333-7

67. Langdon N, Bandak S, Shindler J, Bandak S (1986) Fluoxetine in the treatment of cataplexy. Sleep 9:371-372. https://doi.org/10. 1093/sleep/9.2.371

68. Frey J, Darbonne C (1994) Fluoxetine suppresses human cataplexy: a pilot study. Neurology 44:707-709

69. Thirumalai SS, Shubin RA (2000) The use of citalopram in resistant cataplexy. Sleep Med 1:313-316. https://doi.org/10.1016/ S1389-9457(00)00026-5

70. Poryazova R, Siccoli M, Werth E, Basssetti CL (2005) Unusually prolonged rebound cataplexy after withdrawal of fluoxetine. Neurology 65:967-968. https://doi.org/10.1212/01.wnl. 0000175978.61048 .62

71. Schachter M, Parkes JD (1980) Fluvoxamine and clomipramine in the treatment of cataplexy. JNNP 43:171-174

72. Shapiro WR (1975) Treatment of cataplexy with clomipramine. Arch Neurol 32:653-656. https://doi.org/10.1001/archneur.1975. 00490520023002

73. Guilleminault C, Raynal D, Takahashi S, Carskadon M, Dement W (1976) Evaluation of shortterm and long-term treatment of the narcolepsy syndrome with clomipramine hydrochloride. Acta Neurol Scand 54:71-87. https://doi.org/10.1111/j.1600-0404. 1976.tb07621.x

74. Rugino T (2007) A review of modafinil film-coated tablets for attention deficit/hyperactivity disorder in children and adolescents. Neuropsychiatr Dis Treat 3:293-301
75. Ivanenko A, Tauman R, Gozal D (2003) Modafinil in the treatment of excessive daytime sleepiness in children. Sleep Med 4: 579-582. https://doi.org/10.1007/s13311-012-0149-2

76. Inocente CO, Arnulf I, Bastuji H, Thibault-Stoll A, Raoux A, Reimão R, Lin JS, Franco P (2012) Pitolisant, an inverse agonist of the histamine $\mathrm{H} 3$ receptor: an alternative stimulant for narcolepsy-cataplexy in teenagers with refractory sleepiness. ClinNeuropharmacol 35:55-60. https://doi.org/10.1097/WNF. 0b013e318246879d

77. Moresco M, Pizza F, Antelmi E, Plazzi G (2018) Sodium oxybate treatment in pediatric type 1 narcolepsy. Curr Drug Metab 19: $1073-1079$. ht tps://doi.org/10.2174/ 1389200219666180305153134

78. Murali H, Kotagal S (2006) Off-label treatment of severe childhood narcolepsy-cataplexy with sodium oxybate. Sleep 29:10251029. https://doi.org/10.1093/sleep/29.8.1025

79. Plazzi G, Clawges HM, Owens JA (2018) Clinical characteristics and burden of illness in pediatric patients with narcolepsy. Pediatr Neurol 85:21-32. https://doi.org/10.1016/j.pediatrneurol.2018.06. 008

80. FDA approves new treatment of cataplexy and excessive daytime sleepiness in pediatric patients with narcolepsy- drug information update [news release] (2018) Silver Spring, MD: FDA Division of Drug Information

81. Nishino S, Kotorii N (2016) Modes of action of drugs related to narcolepsy:pharmacology of wake-promoting compounds and anticataplectics. In: Goswami M, Thorpy MJ, Pandi-Perumal SR (eds) Narcolepsy. A clinical guide. Springer International Publishing, Switzerland, pp 307-329

82. Dopheide JA, Pilszka SR (2009) Attention-deficit disorder: an update. Pharmacotherapy 29:656-679

83. Product information (2007) Dextroamphetamine sulfate oral tablets, dextroamphetamine sulfate oral tablets. St. Louis: Mallinckrodt; 2007

84. Product information (2007) RITALIN: oral tablets, methylphenidate hydrochloride oral tablets. East Hanover, NJ: Novartis; 2007

85. Kotagal S (2018) Treatment of narcolepsy and other organic hypersomnias in children. Paediatr Respir Rev 25:19-24. https:// doi.org/10.1016/j.prrv.2017.06.012

86. Ristanovic RK, Llang H, Hornfeldt CS, Lai C (2009) Exacerbation of cataplexy following gradual withdrawal of antidepressants: manifestation of probable protracted rebound cataplexy. Sleep Med 10:416-421. https://doi.org/10.1016/j.sleep. 2008.04.004

87. Lopez R, Dauvilliers Y (2013) Pharmacotherapy options for cataplexy. Expert Opin Pharmacother 14:895-903. https://doi.org/10. 1517/14656566.2013.783021

88. Ratkiewicz M, Splaingard M (2013) Treatment of cataplexy in a three-year-old using venlafaxine. J Clin Sleep Med 15:13411342. https://doi.org/10.5664/jcsm.3284

89. Moller L, Ostergaard J (2009) Treatment with venlafaxine in six cases of children with narcolepsy with cataplexy and hypnagogic hallucinations. J Child Adolesc Psychopharmacol 19:197-201. https://doi.org/10.1089/cap.2008.036

90. Plazzi G, Poli F, Franceschini C, Parmeggiani A, Pirazzoli P, Bernardi F, Mignot E, Cicognani A, Montagna P (2008) Intravenous high-dose immunoglobulin treatment in recent onset childhood narcolepsy with cataplexy. J Neurol 255:1549-1554. https://doi.org/10.1007/s00415-008-0983-7

91. Knudsen S, Biering-Sørensen B, Kornum BR, Petersen ER, Ibsen JD, Gammeltoft S, Mignot E, Jennum PJ (2012) Early IVIg treatment has no effect on post-H1N1 narcolepsy phenotype or hypocretin deficiency. Neurology 3:102-103. https://doi.org/10. 1212/WNL.0b013e31825dce03

92. Lecendreux M, Berthier J, Corny J, Bourdon O, Dossier C, Delclaux C (2017) Intravenous immunoglobulin therapy in 
pediatric narcolepsy: a nonrandomized, open-label, controlled, longitudinal observational study. J Clin Sleep Med 15:441-453. https://doi.org/10.5664/jcsm. 6500

93. Ruppert E, Zagala H, Chambe J, Comtet H, Kilic-Huck U, Lefebvre F, Bataillard M, Schroder C, Calvel L, Bourgin P (2018) Intravenous immunoglobulin therapy administered early after narcolepsy type 1 onset in three patients evaluated by clinical and polysomnographic follow-up. BehavNeurol15;2018: 1671072. https://doi.org/10.1155/2018/1671072

94. Pizza F, Franceschini C, Peltola H (2013) Clinical and polysomnographic course of childhood narcolepsy with cataplexy. Brain 136:3787-3795. https://doi.org/10.1093/brain/awt277

95. Donjacour C, Mets MAJ, Verster JC (2010) Narcolepsy, driving and traffic safety. In: Goswami M, Pandi-Perumal SR, Thorpy MJ (eds) Narcolepsy: a clinical guide. Springer Humana Press, New York, pp 217-222

96. Lindsley G (2010) Narcolepsy, intimacy and sexuality. In: Goswami M, Pandi-Perumal SR, Thorpy MJ (eds) Narcolepsy: a clinical guide. Springer Humana Press, New York, pp 205-216

97. Naumann A, Bellebaum C, Daum I (2006) Cognitive deficits in narcolepsy. J Sleep Res 15:329-338. https://doi.org/10.1111/j. 1365-2869.2006.00533.x

98. Bellebaum C, Daum I (2010) Memory and cognition in narcolepsy. In: Goswami M, Pandi-Perumal SR, Thorpy MJ (eds) Narcolepsy: a clinical guide. Springer Humana Press, New York, pp 223-230

99. Vignatelli L, Plazzi G, Peschechera F, Delaj L, D'Alessandro R (2011) A 5-year prospective cohort study on health-related quality of life in patients with narcolepsy. Sleep Med 12:19-23. https:// doi.org/10.1016/j.sleep.2010.07.008

100. Ingravallo F, Plazzi G (2010) Medico-legal aspects of disability in narcolepsy. In: Goswami M, Pandi-Perumal SR, Thorpy MJ (eds) Narcolepsy: a clinical guide. Springer Humana Press, New York, pp 231-238

101. Shneerson J (2010) Narcolepsy and mental health. In: Goswami M, Pandi-Perumal SR, Thorpy MJ (eds) Narcolepsy: a clinical guide. Springer Humana Press, New York, pp 239-250

102. Britton T, Hansen A, Hicks J, Howard R, Meredith A (2002) Guidelines on the diagnosis and management of narcolepsy in adults and children. Evidence-based guidelines for the UK with graded recommendations. Taylor Patten Communications Ltd, Ashtead

103. Billiard M, QueraSalva M, de Koninck J, Besset A, Touchon J, Cahilhac J (1986) Daytime sleep characteristics and night sleep in the narcoleptic patient. Sleep 9:167-174. https://doi.org/10.1093/ sleep/9.1.167

104. Overeem S, Reading P, Bassetti CL (2012) Narcolepsy. Sleep Med Clin 7:263-281

105. Krahn LE, Hershner S, Loeding LD, Maski KP, Rifkin DI, Selim B, Watson NF (2015) Quality measures for the care of patients with narcolepsy. J Clin Sleep Med 11:335. https://doi.org/10.5664/ jcsm.4554

106. Mullington J, Broughton R (1993) Scheduled naps in the management of daytime sleepiness in narcolepsy cataplexy. Sleep 16:444 456. https://doi.org/10.1093/sleep/16.5.444

107. Yuchiyama MG, Mayer G, Meier-Ewert K (1994) Differential effects of extended sleep in narcoleptics patients. Electroencephalogr Clin Neurophysiol 91:212-218

108. Bhattarai J, Sumerall S (2017) Current and future treatment options for narcolepsy: a review. Sleep Sci 10:19-27. https://doi.org/ 10.5935/1984-0063.20170004

109. Rogers AE (1984) Problems and coping strategies identified by narcoleptic patients. J Neurosurg Nurs 16:326-334

110. Bruck D, Broughton R (2001) Achieving control over sleepiness in narcolepsy. Aust J Prim Health 7:16-24
111. Marin-Agudelo H (2011) Multicomponent cognitive behavioral treatment efficacy for narcolepsy (MCBT-N). Sleep Med 12: S55-S42. https://doi.org/10.1016/j.slsci.2014.07.023

112. Conroy DA, Novick DM, Swanson LM (2012) Behavioral management of hypersomnia. Sleep Med Clin 7:325-331

113. Marín-Agudelo H, Jiménez Correa U (2012) Scheduled naps and systematic desensitization in the emotional processing in patients with narcolepsy: a comparative study of autonomic and cognitive evoked potentials. Sleep 35:A275

114. Marín-Agudelo H, Jiménez Correa U (2013) Beliefs and dysfunctional attitudes in patients with narcolepsy; double-blind study of treatment efficacy. Sleep 36(Suppl: A256)

115. Espana RA, McCormack SL, Mochizuki T, Scammell TE (2007) Running promotes wakefulness and increases cataplexy in orexin knockout mice. Sleep 30:1417-1425. https://doi.org/10.1093/ sleep/30.11.1417

116. Filardi M, Pizza F, Antelmi E, Pillastrini P, Natale V, Plazzi G (2018) Physical activity and sleep/wake behavior, anthropometric, and metabolic profile in pediatric narcolepsy type 1. Front Neurol 9:707. https://doi.org/10.3389/fneur.2018.00707

117. MarínAgudelo HA, Jiménez Correa U, Carlos Sierra J, PandiPerumal SR, Schenck CH (2014) Cognitive behavioral treatment for narcolepsy: can it complement pharmacotherapy? Sleep Sci 7: 30-42. https://doi.org/10.1016/j.slsci.2014.07.023

118. Dennis CL (2003) Peer support within a health care context: a concept analysis. Int J Nurs Stud 40:321-332. https://doi.org/10. 1016/S0020-7489(02)00092-5

119. Embuldeniya G, Veinot P, Bell E, Nyhof-Young J, Sale JE, Britten N (2013) The experience and impact of chronic disease peer support interventions: a qualitative synthesis. Patient Educ Couns 92: 3-12. https://doi.org/10.1016/j.pec.2013.02.002

120. Shilling V, Morris C, Thompson-Coon J, Ukoumunne O, Rogers M, Logan S (2013) Peer support for parents of children with chronic disabling conditions: a systematic review of quantitative and qualitative studies. Dev Med Child Neurol 55:602-609. https://doi.org/10.1111/dmen.12091

121. Anderson M, Elliott EJ, Zurynski YA (2013) Australian families living with rare disease: experiences of diagnosis, health services use and needs for psychosocial support. Orphanet J Rare Dis 8:19. https://doi.org/10.1186/1750-1172-8-22

122. Kippola-Pääkkönen A, Härkäpää K, Valkonen J, TuulioHenriksson A, Autti-Rämö I (2016) Psychosocial intervention for children with narcolepsy: parents' expectations and perceived support. J Child Health Care 20:521-529. https://doi.org/10.1177/ 1367493516643420

123. Dauvilliers Y, Roth T, Giunta D et al (2017) Effect of sodium oxybate, modafinil, and their combination on disrupted nighttime sleep in narcolepsy. Sleep Med 40:53-57. https://doi.org/10.1016/ j.sleep.2017.07.030

124. Roth T, Dauvilliers Y, Mignot E, Montplaisir J, Paul J, Swick T, Zee P (2013) Disrupted nighttime sleep in narcolepsy. J Clin Sleep 9:955-965. https://doi.org/10.5664/jcsm.3004

125. European Commission (2014) Implementation report on the commission communication on rare diseases: Europe's challenges and council recommendation of 8 June 2009 on an action in the field of rare diseases. Available at: http://ec.europa.eu/health/rare diseases/docs/2014_rarediseases_implementationreport_en.pdf

Publisher's note Springer Nature remains neutral with regard to jurisdictional claims in published maps and institutional affiliations. 